\title{
Chapter 30 \\ An Elemental Fractionation Mechanism \\ Common to Biogenic Calcium Carbonate
}

\author{
Kotaro Shirai
}

\begin{abstract}
Biological modulation of element incorporation presents a major hurdle in the interpretation of geochemical data as an environmental proxy, detailed understanding and quantitative evaluation of the mechanism of elemental fractionation both being essential for reliable reconstruction of an environment. Biogenic calcium carbonate has a specific skeletal microstructure, which is strongly controlled by biomineralization. Since primary processes are more likely reflected on a smaller spatial scale, elemental distribution patterns associated with skeletal microstructure should provide unique information on biological elemental fluctuations, which cannot be determined from large-scale analysis. To study elemental fractionation mechanisms, microscale elemental distribution patterns have been studied in coral skeletons and bivalve and foraminiferal shells and the skeletal microstructure, sulfur distribution, and organic features compared. The microanalytical studies revealed two characteristic patterns that were common to all studied biogenic calcium carbonates, even though the specimens examined represented different phyla: (1) significant compositional heterogeneities that could not be explained by changes in the ambient environment and (2) a strong correlation of "metal/Ca" ratios with all or some of sulfur distribution, skeletal microstructure, and organic character. Based on these common features, I propose a mechanism of elemental fractionation, commonly applicable to biogenic calcium carbonates and involving both composition and/or concentration of organics in the calcifying fluid, that facilitates preferential elemental incorporation into biogenic calcium carbonate.
\end{abstract}

Keywords Biogenic calcium carbonate $\cdot$ Proxy $\cdot$ Vital effect $\cdot$ Geochemistry · Trace element $\cdot$ Coral $\cdot$ Bivalve shell $\cdot$ Foraminifera $\cdot$ Sclerosponge

\footnotetext{
K. Shirai $(\square)$

Atmosphere and Ocean Research Institute, The University of Tokyo, Kashiwa, Chiba, Japan e-mail: kshirai@aori.u-tokyo.ac.jp
} 


\subsection{Introduction}

$\mathrm{Mg} / \mathrm{Ca}$ and $\mathrm{Sr} / \mathrm{Ca}$ ratios in biogenic calcium carbonate are widely used as proxies for estimating past seawater temperatures (e.g., Henderson 2002; Lea 2003). However, such ratios are also more or less affected by biological processes, socalled vital effects (Cohen and McConnaughey 2003). For example, the Sr/Ca ratio in a coral skeleton (aragonite) and $\mathrm{Mg} / \mathrm{Ca}$ ratio in a foraminiferan test (calcite) reflect temperature relatively precisely (Lea 2003), whereas $\mathrm{Mg} / \mathrm{Ca}$ in the former and $\mathrm{Sr} / \mathrm{Ca}$ in the latter, and both ratios in bivalve shells (both aragonite and calcite), are susceptible to biological modulation (Schöne 2013). Although the vital effect is considered to be species-specific, it remains a major hurdle to interpreting geochemical data as an environmental proxy, as the ultimate mechanism governing elemental fractionation, a detailed understanding and quantitative evaluation of which is essential for reliable past environment reconstruction, is still unclear.

A fundamental question concerns the common existence or otherwise of an elemental fractionation mechanism in any biogenic calcium carbonate. Biomineralization can be interpreted as inorganic mineralization strongly controlled by soluble and insoluble organic materials, as well as physiological control, such as that exerted by $\mathrm{pH}$, physical structure, space regulations, and ion transportation (e.g., Marin et al. 2008). Thus, the relationship between micrometer-scale elemental distribution and microstructure may provide a unique opportunity to investigate the mechanism of element fractionation by biological processes. The aim of the present study was to examine a common, cross-phylum fractionation mechanism based on microscale elemental distribution in coral skeletons and bivalve and foraminiferal shells, comparing elemental distribution, skeletal/shell microstructure, sulfur distribution, and organic features.

\subsection{Materials and Methods}

The examined samples included the reef building branching coral Acropora nobilis (Shirai et al. 2008a), deep sea solitary coral Caryophyllia ambrosia ambrosia (Shirai et al. 2005), ocean quahog Arctica islandica (Shirai et al. 2014), deep sea hydrothermal mussel Bathymodiolus platifrons (Shirai et al. 2008b), and planktonic foraminifera Globorotalia menardii (Kunioka et al. 2006). Samples were cleaned, embedded in epoxy resin, sectioned, polished, metal coated where necessary, and analyzed by electron probe microanalysis (EPMA) or high lateral resolution secondary ion mass spectrometry (NanoSIMS). The microstructure was observed by SEM or optical microscope following etching/staining by Mutvei's solution (Schöne et al. 2005). Specific details of sample origin and preparation and analytical methods are included in the above-cited references. 


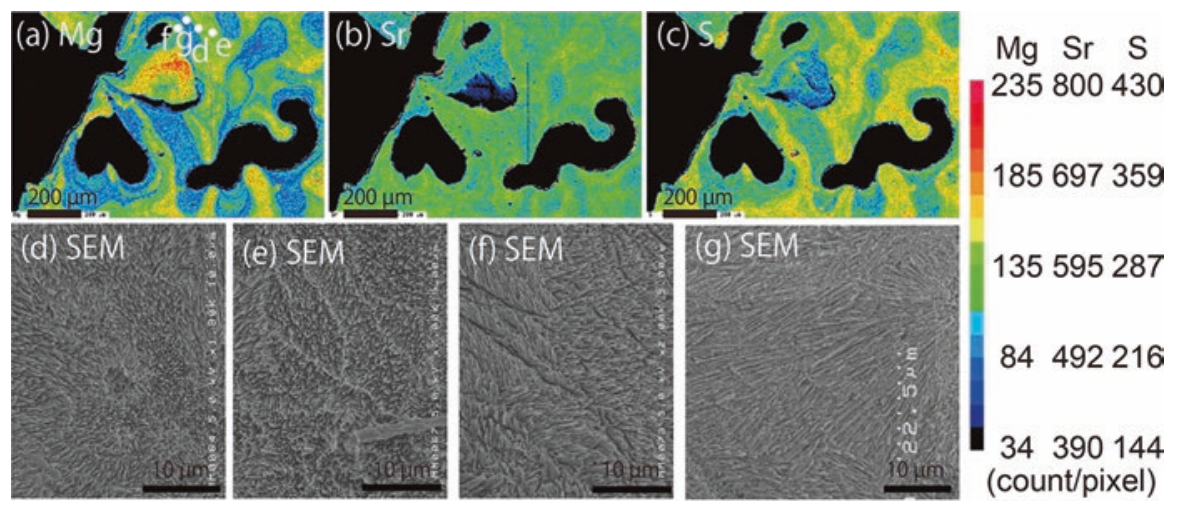

Fig. 30.1 Elemental distribution and skeletal microstructure of branching coral Acropora nobilis. (a) EPMA Mg map. (b) EPMA Sr map. (c) EPMA S map. (d-g) Skeletal microstructure of polished-etched surface by SEM. (Figures modified from Shirai et al. 2008a). Color scale bar on right indicates gross count per pixel

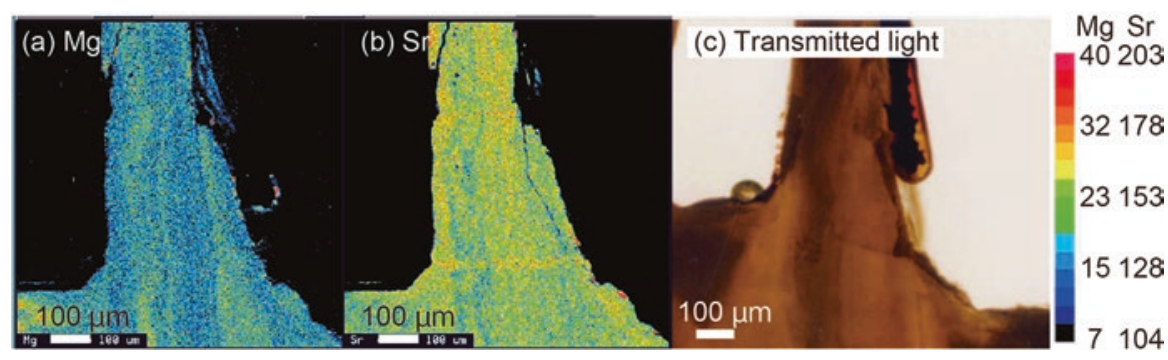

Fig. 30.2 Elemental distribution and skeletal microstructure of deep sea coral Caryophyllia ambrosia ambrosia. (a) EPMA Mg map. (b) EPMA Sr map. (c) Skeletal microstructure observed in thin section under transmitted light microscopy. (Figures modified from Shirai et al. 2005). Color scale bar on right indicates gross count per pixel

\subsection{Results}

Elemental distribution and skeletal/shell microstructure of the examined samples are shown in Figs. 30.1, 30.2, 30.3, 30.4, and 30.5. Regardless of mineralogy and phylum, the following were common at the microscale level in all of the examined biogenic carbonates: (1) large compositional heterogeneity and (2) element/Ca ratios, skeletal/shell microstructure, sulfur distribution, and insoluble skeletal organic characters all correlated (nonlinear) with one another. 

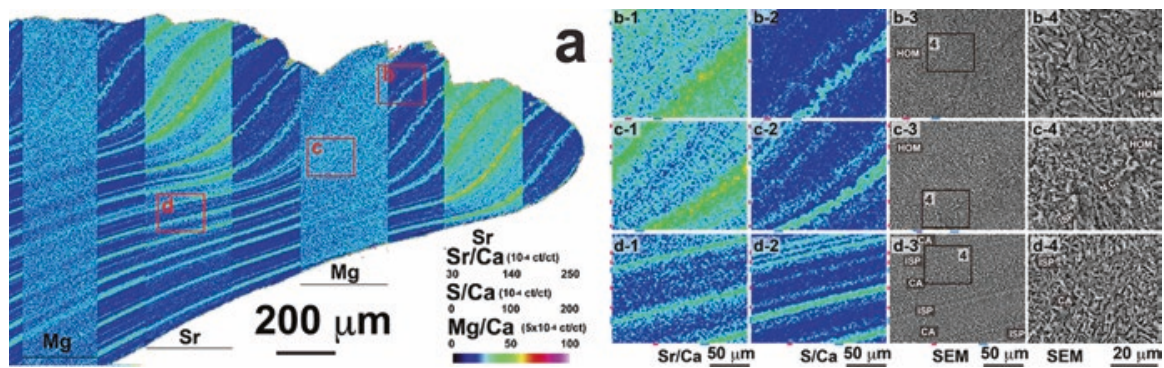

Fig. 30.3 Elemental distribution and shell microstructure of ocean quahog Arctica islandica. (a) $\mathrm{Sr} / \mathrm{Ca}$ and $\mathrm{Mg} / \mathrm{Ca}$ maps partly overlapped on S/Ca map. (b-d) High-magnification images of elemental maps and shell microstructure along sixth annual growth line from ventral margin (red rectangles in (a)). From left to right, (1) EPMA Sr/Ca map, (2) EPMA S/Ca map, (3) SEM microstructure image, and (4) inset of (3). HOM homogeneous structure, ISP irregular simple prismatic structure, $C A$ crossed acicular structure, N.C. shell microstructure is not clear. (Figures modified from Shirai et al. 2014). Color scale bar on bottom right in panel (a) indicates gross count ratio (ct/ ct count/count) per pixel

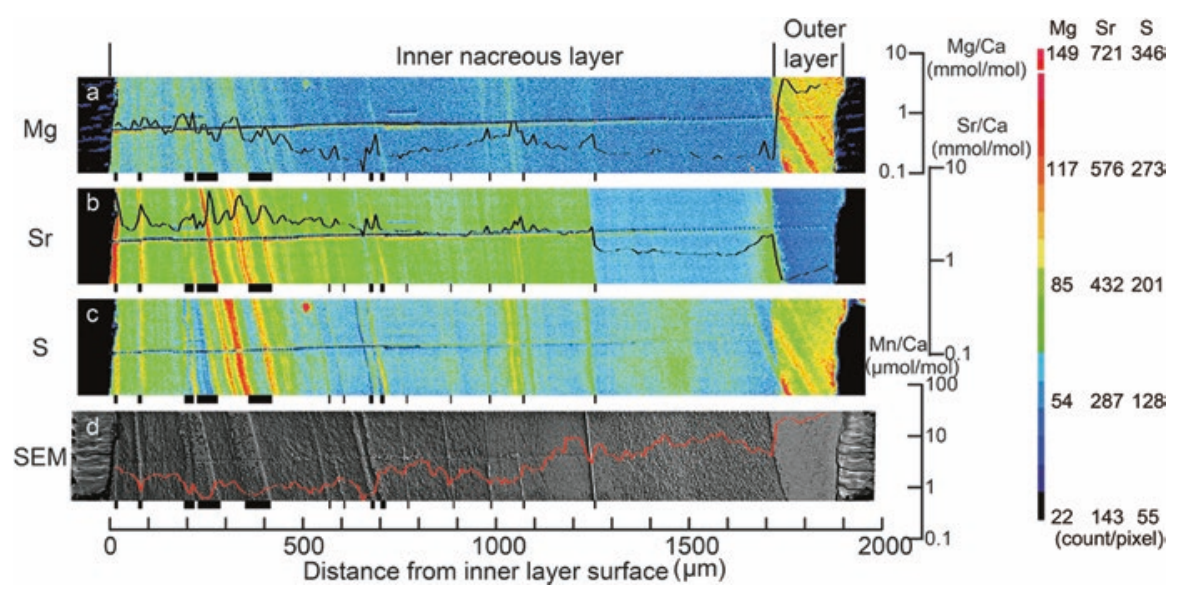

Fig. 30.4 Elemental distribution and shell microstructure of hydrothermal mussel Bathymodiolus platifrons. (a) EPMA Mg map with NanoSIMS Mg/Ca profile overlaid (right axis for scale). (b) EPMA Sr map with NanoSIMS Sr/Ca profile overlaid. (c) EPMA S map. (d) Shell microstructure of polished-etched surface by SEM with NanoSIMS Mn/Ca profile overlaid. (Figures modified from Shirai et al. 2008b)

\subsection{Discussion}

The correlation with microstructure suggests that microscale heterogeneity is likely induced by the biomineralization processes, the magnitude of variation being too great to be explained by ambient environmental changes. Similar correlations between chemical composition and microstructure have been documented in other coral skeleton studies (e.g., Meibom et al. 2004, 2008), bivalve shell 


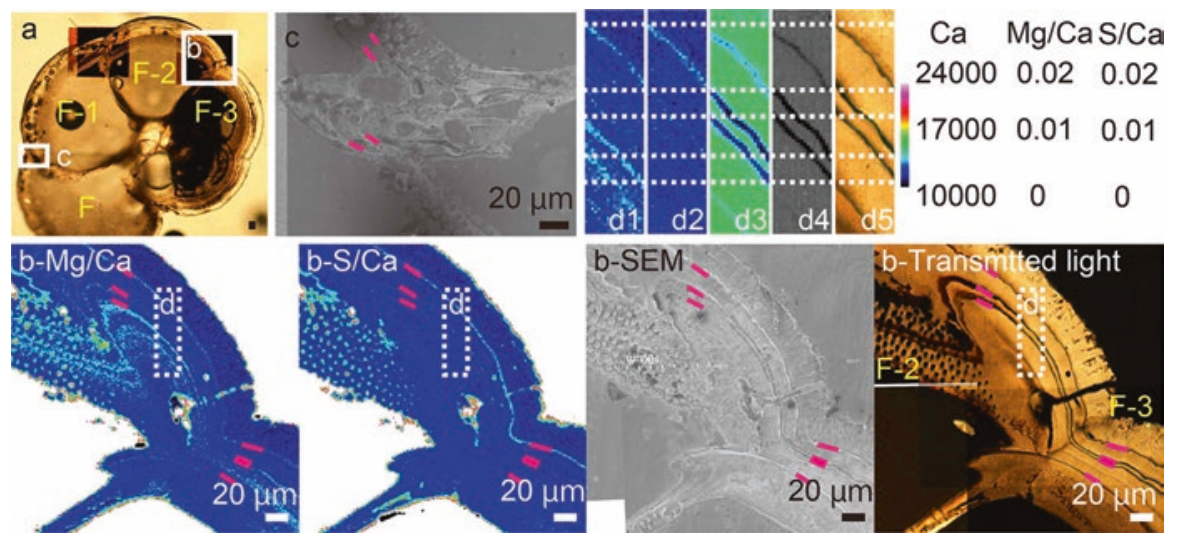

Fig. 30.5 Elemental distribution and shell microstructure of planktonic foraminifera Globorotalia menardii. (a) Shell microstructure under transmitted light microscopy after EPMA analysis (b) From left to right, EPMA Mg/Ca map, EPMA S/Ca map, shell microstructure of polished-etched surface by SEM and transmitted light microscope image. (c) SEM microstructure image, enlargements of inset of (a). (d) Enlargements of inset of (b). From left to right, (d1) EPMA Mg/Ca map, (d2) EPMA S/Ca map, (d3) EPMA Ca map, (d4) EPMA backscattered electron image, and (d5) transmitted light microscope image. Pink bars represent organic membrane. White dashed lines in (d) act as a guide for comparing each figure on the same position

(Dauphin et al. 2005, 2013; Füllenbach et al. 2017), foraminifera (Sadekov et al. 2005; Kunioka et al. 2006), brachiopod (Pérez-Huerta et al. 2011), and Ostracoda (Morishita et al. 2007), being lines of evidence pointing to an almost universal relationship between elemental distribution and microstructure in any biogenic calcium carbonate, as well as suggesting the existence of a common physiochemical mechanism governing elemental fractionation.

Recent studies have reported that organic molecules present in the calcifying solution enhance $\mathrm{Mg}$ incorporation in inorganically precipitated calcite (Stephenson et al. 2008) and amorphous calcium carbonate (Wang et al. 2009). In the latter model, aqueous carboxylated molecules, which have greater selectivity for binding to $\mathrm{Ca}$ than $\mathrm{Mg}$, increase the relative activity of $\mathrm{Mg}$ against $\mathrm{Ca}$ in the solution, producing high $\mathrm{Mg} / \mathrm{Ca}$ amorphous calcium carbonate, considered a precursor phase of crystalline carbonate (e.g., Pouget et al. 2009). Thus, organically mediated fractionation processes may occur in the early stages of crystallization (Wang et al. 2009), with the mechanism that determines the composition of amorphous calcium carbonate also likely controlling biogenic calcite composition. Since the organic membrane has a characteristic electrostatic structure regulating biomineralization (e.g., Marin et al. 2008; Ren et al. 2011), it is also possible that such a structure of insoluble organics influences elemental incorporation into carbonate. Since biomineralization occurs in calcifying fluid (or calcifying space), the organic (and inorganic) composition of which is highly regulated by the organism, I suggest that both soluble and insoluble organic composition and concentration in calcifying fluids control the microscale elemental distribution commonly found in biogenic calcium 
carbonate. Changes in the microstructure and sulfur distribution can be considered as signatures of change in the organic composition and sulfur-containing organic matrix in the calcifying medium, respectively. These processes are likely common in any biomineralization. Such an organically mediated fractionation hypothesis can also explain why elemental composition is not correlated with other elements in a quantitative manner, since the function of macromolecules in calcium carbonate precipitation depends not only on their structure and composition but also on their supramolecular assemblage (e.g., Marin et al. 2008). A detailed discussion of this elemental fractionation mechanism is reported in Shirai et al. (2014) and Füllenbach et al. (2017).

\section{References}

Cohen AL, McConnaughey TA (2003) Geochemical perspectives on coral mineralization. Rev Mineral Geochem 54:151-187

Dauphin Y, Cuif JP, Salome C, Susini J (2005) Speciation and distribution of sulfur in a mollusk shell as revealed by in situ maps using X-ray absorption near-edge structure (XANES) spectroscopy at the SK-edge. Am Mineral 90:1748-1758

Dauphin Y, Ball AD, Castillo-Michel H, Chevallard C, Cuif JP, Farre B, Pouvreau S, Salome M (2013) In situ distribution and characterization of the organic content of the oyster shell Crassostrea gigas (Mollusca, Bivalvia). Micron 44:373-383

Füllenbach CS, Schöne BR, Shirai K, Takahata N, Ishida A, Sano Y (2017) Minute co-variations of $\mathrm{Sr} / \mathrm{Ca}$ ratios and microstructures in the aragonitic shell of Cerastoderma edule (Bivalvia)-are geochemical variations at the ultra-scale masking potential environmental signals? Geochim Cosmochim Acta 205:256-271

Henderson GM (2002) New oceanic proxies for paleoclimate. Earth Planet Sci Lett 203:1-13

Kunioka D, Shirai K, Takahata N, Sano Y, Toyofuku T, Ujiie Y (2006) Microdistribution of Mg/Ca, $\mathrm{Sr} / \mathrm{Ca}$, and $\mathrm{Ba} / \mathrm{Ca}$ ratios in Pulleniatina obliquiloculata test by using a Nano-SIMS: implication for the vital effect mechanism. Geochem Geophys Geosyst 7:Q12P20

Lea DW (2003) Elemental and isotopic proxies of past ocean temperatures. Treat Geochem 6:365-390

Marin F, Luquet G, Marie B, Medakovic D (2008) Molluscan shell proteins: primary structure, origin, and evolution. Curr Top Dev Biol 80:209-276

Meibom A, Cuif JP, Hillion FO, Constantz BR, Juillet-Leclerc A, Dauphin Y, Watanabe T, Dunbar RB (2004) Distribution of magnesium in coral skeleton. Geophys Res Lett 31:L23306

Meibom A, Cuif JP, Houlbreque F, Mostefaoui S, Dauphin Y, Meibom KL, Dunbar R (2008) Compositional variations at ultra-structure length scales in coral skeleton. Geochim Cosmochim Acta $72: 1555-1569$

Morishita T, Tsurumi A, Kamiya T (2007) Magnesium and strontium distributions within valves of a recent marine ostracode, Neonesidea oligodentata: implications for paleoenvironmental reconstructions. Geochem Geophys Geosyst 8:GC001585

Pérez-Huerta A, Cusack M, Dalbeck P (2011) Crystallographic contribution to the vital effect in biogenic carbonates Mg/Ca thermometry. Earth Env Sci Trans Roy Soc Edinbur 102:35-41

Pouget EM, Bomans PHH, Goos JACM, Frederik PM, de With G, Sommerdijk NAJM (2009) The initial stages of template-controlled $\mathrm{CaCO} 3$ formation revealed by Cryo-TEM. Science 323:1455-1458

Ren D, Feng Q, Bourrat X (2011) Effects of additives and templates on calcium carbonate mineralization in vitro. Micron 2:228-245 
Sadekov AY, Eggins SM, De Deckker P (2005) Characterization of Mg/Ca distributions in planktonic foraminifera species by electron microprobe mapping. Geochem Geophys Geosyst 6:GC000973

Schöne BR (2013) Arctica islandica (Bivalvia): a unique paleoenvironmental archive of the northern North Atlantic Ocean. Glob Planet Chang 111:199-225

Schöne BR, Dunca E, Fiebig J, Pfeiffer M (2005) Mutvei's solution: an ideal agent for resolving microgrowth structures of biogenic carbonates. Palaeogeogr Palaeoclimatol Palaeoecol 228:149-166

Shirai K, Kusakabe M, Nakai S, Ishii T, Watanabe T, Hiyagon H, Sano Y (2005) Deep-sea coral geochemistry: implication for the vital effect. Chem Geol 224:212-222

Shirai K, Kawashima T, Sowa K, Watanabe T, Nakaniori T, Takahata N, Arnakawa H, Sano Y (2008a) Minor and trace element incorporation into branching coral Acropora nobilis skeleton. Geochim Cosmochim Acta 72:5386-5400

Shirai K, Takahata N, Yamamoto H, Omata T, Sasaki T, Sano Y (2008b) Novel analytical approach to bivalve shell biogeochemistry: a case study of hydrothermal mussel shell. Geochem J 42:413-420

Shirai K, Schöne BR, Miyaji T, Radermacher P, Krause RA Jr, Tanabe K (2014) Assessment of the mechanism of elemental incorporation into bivalve shells (Arctica islandica) based on elemental distribution at the microstructural scale. Geochim Cosmochim Acta 126:307-320

Stephenson AE, DeYoreo JJ, Wu L, Wu KJ, Hoyer J, Dove PM (2008) Peptides enhance magnesium signature in calcite: insights into origins of vital effects. Science 322:724-727

Wang DB, Wallace AF, De Yoreo JJ, Dove PM (2009) Carboxylated molecules regulate magnesium content of amorphous calcium carbonates during calcification. Proc Natl Acad Sci U S A 106:21511-21516

Open Access This chapter is licensed under the terms of the Creative Commons Attribution 4.0 International License (http://creativecommons.org/licenses/by/4.0/), which permits use, sharing, adaptation, distribution and reproduction in any medium or format, as long as you give appropriate credit to the original author(s) and the source, provide a link to the Creative Commons license and indicate if changes were made.

The images or other third party material in this chapter are included in the chapter's Creative Commons license, unless indicated otherwise in a credit line to the material. If material is not included in the chapter's Creative Commons license and your intended use is not permitted by statutory regulation or exceeds the permitted use, you will need to obtain permission directly from the copyright holder. 